\title{
Pelatihan Mengolah Limbah Sapi menjadi Pupuk di Desa Nagasari, Kecamatan Serang Baru, Kabupaten Bekasi
}

\author{
Istianah Setyaningsih, Alfyyah Widad, Sri Mulyati, Wahid Dasa Ridwani \\ Program Studi Ilmu Administrasi Publik \\ Fakultas Ilmu Administrasi, Institut STIAMI \\ istianah@stiami.ac.id, alfyyahwidad1998@gmail.com, sriribel07@gmail.com ,wahiddasaridwani@gmail.com
}

\section{ARTICLE INFO}

Keyword:

Training,organic

fertilizer,

cow dung

\section{$A B S T R A C T$}

Nagasari Village is one of the villages in Serang Baru Sub-district, Bekasi Regency, the majority of the population in this village as farmers and ranchers. The high number of people who have cattle in Nagasari village raises the problem for the village, namely the high number of cow dung waste. The confinement of knowledge both theoretically and practically related to the utilization of cow dung waste, causing the community to only dispose of and burn cow dung without exploiting it. Based on the problem, we take the initiative to provide counseling and training on how to make organic fertilizer from cow dung. The process is done through socialization to the community, then conducted teaching on the method of implementing the implementation of the Hajj fertilizer from cow dung. The next step is the process of making and fermentation fertilizer. The results obtained by the enable will be applied to the community Tanamman and distributed or sold with organic fertilizer label Village.

\section{Pendahuluan}

Indonesia merupakan negara agraris, dimana $40 \%$ mata pencaharian mayoritas penduduknya bertani atau bertanam cocok. Hal ini didukung dengan luas lahan serta keanekaragaman hayati , serta iklim yang mendukung untuk bercocok tanam. Selain profesi sebagai petani, tidak sedikit masyarakat Indonesia menjadi peternak, baik peternak ayam, kambing maupun sapi di berbagai daerah. Proses pengelolaan lahan pertanian sangat membutuhkan pupuk sebagai penunjang agar tanah tetap subur serta menambah jumlah produksi hasil pertanian.

Sejak adanya pupuk anorganik mengakibatkan petani beralih pada penggunaan pupuk anorganik, selain mudah didapatkan pupuk anorganik ini juga persediaannya tercukupi. Pupuk anorganik adalah pupuk yang dibuat dengan campuran bahan kimia yang kan menyebabkan meningkatnya populasi tanah sehingga berdampak pada kesehatan para petani itu sendiri. Data dari BPS melalui sensus Pertanian pada 2013, petani yang menggunakan pupuk anorganik mencapai 86,41 persen. Sementara, penggunaan pupuk berimbang (organik dan anorganik) hanya 13,5 persen dan organik 0,07 persen. Maka para petani hanya memikirkan hasil produksi tanpa memikirkan dampak yang akan ditimbulkan dari penggunaan pupuk anorganik secara terus menerus. Untuk mendorong petani mengurangi penggunaan pupuk anorganik maka pemerintah membuat Peraturan Menteria Pertanian (Permentan) No. 70 Tahun 2011 tentang Pupuk Organik, Pupuk Hayati dan Pembenah Tanah, peraturan ini mendorong munculnya usaha pengolahan pupuk organic.

Desa Nagasari merupakan desa yang terletak di Kecamatan Serang Baru, Kabupaten Bekasi, Provinsi Jawa Barat dengan mayoritas mata pencaharian petani, dan peternak. Tingginya jumlah penduduk yang bermata pencaharian sebagai peternak menyebabkan jumlah limbah kotoran hewan 
yang dihasilkan cukup banyak. Limah kotoran sapi yang berada di Desa Nagasari cenderung tidak dimanfaatkan oleh penduduk, atau bahkan hanya dibiarkan menumpuk di pinggir jalan sehingga keberadaannya justu menganggu bagi warga yang melintasi jalan-jalan tersebut.

Kotoran hewan adalah sumber nutrisi yang baik untuk menambah kesuburan tanaman. Untuk membuat kotoran hewan bisa digunakan secara maksimal, maka kotoran hewan tersebut perlu diolah menjadi pupuk kompos terlebih dahulu sebelum dapat digunakan sebagai pupuk pada tumbuhan maupun tanah.

Berikut Manfaat Pupuk organik dari kotoran Sapi :

1. Memperbaiki struktur tanah berlempung sehingga menjadi ringan.

2. Memperkuat daya ikat tanah berpasir sehingga tanah tidak berderai.

3. Menambah daya ikat tanah kepada air dan unsur-unsur hara tanah.

4. Memiliki unsur hara yang lengkap.

5. Membantu proses pelapukan bahan mineral.

6. Memberikan ketersediaan bahan makanan untuk mikroba.

7. Menurunkan aktivitas mikroorganisme merugikan.

\section{Masalah}

Problematika yang ada di desa tersebut yaitu kurangnya pengetahuan tentang sumber daya alam yang berpotensi nilai ekonomis, salah satunya adalah kotoran sapi. Dimana mereka hanya membuang dan membakarnya tanpa dimanfaatkan. Kurangnya pengetahuan baik secara teoritis maupun praktek mengenai manfaat, fungsi, dan cara membuat pupuk organik membuat sebagian besar warga desa Nagasari menggunakan pupuk kimia atau pupuk anorganik sebagai bahan utama untuk meningkatkan hasil pertanian mereka. Masyarakat atau petani belum begitu paham bahwa untuk jangka panjang penggunaan pupuk anorganik akan mengikis unsur hara dan berbagai mineral penting dalam tanah sehingga menyebabkan tanah menjadi kurang subur.

\section{Gambaran Umum Masyarakat Sasaran}

\subsection{Lokasi}

Desa Nagasari merupakan salahs atu dari delapan desa di wilayah kecamatan Serang Baru yang terletak 20 KM kearah ibukota dari kecamatan Serang Baru. Desa Nagasari mempunyai luas wilayah seluas \pm 786.867 hekktar. Iklim desa Nagasari sebagaimana desa lain di wilayah Indonesia mempunyai iklim kemarau dan penghujan, hal tersebut mempunyai pengaruh langsung terhadap pola tanam yang ada di desa Nagasari. Desa Nagasari mempunyai jumlah penduduk 4.618 jiwa, yang tersebar dalam tiga dusun. Mayoritas penduduk desa Nagasari yaitu petani dan peternak, hal ini bisa dijadikan bahan untuk pengoptimalan ekonomi masyarakat melalui pemanfaatan kotoran sapi yang diolah mmenjadi pupuk organik.

\subsection{Sasaran}

Sasaran program pengabdian masyarakat ini adalah seluruh masyarakat desa Nagasari terutama yang berprofesi sebagai petani dan peternak.

\subsection{Kondisi Sosial dan Ekonomi Sasaran}

\section{Kondisi Sosial}


Sebagian besar mayarakat desa Nagasari bermata pencaharian sebagai petani dan peternak dan adapula yang bermatapencaharian sebagai penjual warung dan toko kecil dan lain-lain.

Menurut data terbaru Kepala Desa Nagasari tahun 2018, riwayat pendikan masyarakat Desa Nagasari masih rendah. Hal ini mengakibatkan kurangnya pengetahuan masyarakat terhadap metode yang tepat dalam pengolahan produk yang berasal dari kotoran sapi. Oleh karena itu perlu adanya pelatihan skill terhadap masyarakat Desa Nagasari.

\section{Kondisi Ekonomi}

Berdasarkan data kantor kepala Desa setempat tahun 2018 masyarakat di Desa Nagasari secara ekonomi sudah mencapai taraf yang cukup baik.

\subsection{Permasalahan Yang Dihadapi Masyarakat Sasaran}

Permasalahan utama di Desa Nagasari adalah minimnya pengeetahuan mengenai pengelolaan sumber daya alam serta potensi yang ada di Desa tersebut. Salah satu penyebab hal tersebut dikarenakan tingkat pendidikan yang rendah, sehingga terbatasnya informasi terkait pemanfaatan kotoran hewan. Selain itu mayoritas masyarakatnya adalah peternak dan petani, hal ini memungkinkan untuk adanya pengelolaan kotoran sapi menjadi pupuk organik yang bermanfaat.

Tabel 3.1

Permasalahan di Desa Nagasari

\begin{tabular}{|l|l|}
\hline Permasalahan & Solusi \\
\hline $\begin{array}{l}\text { Masyarakat yang berprofesi sebagai petani } \\
\text { cenderung } \\
\text { mengelola pertaniannya dengan membeli pupuk, } \\
\text { sehingga hal ini menambah biaya dalam proses } \\
\text { pertanian. }\end{array}$ & $\begin{array}{l}\text { Menjadi pupuk organik yang } \\
\text { bermanfaat untuk proses } \\
\text { pertanian. }\end{array}$ \\
$\begin{array}{l}\text { Masyarakat yang menjadi peternak sapi tidak } \\
\text { memanfaatkan kotoran sapi (dibakar/ dibuang) }\end{array}$ & \\
\hline
\end{tabular}

\section{Metode Pelaksanaan Dan Jadwal Kegiatan}

Tabel 4.1

Metode Pelaksanaan

\begin{tabular}{|l|l|l|l|}
\hline \multirow{2}{*}{ NO } & \multicolumn{2}{|c|}{ METODE PELAKSANAAN } & \multirow{2}{*}{$\begin{array}{c}\text { INDIKATOR } \\
\text { KEBERHASILAN }\end{array}$} \\
\cline { 2 - 3 } & Tahap & Bentuk Kegiatan & \\
\hline 1. & Perencanaan & Pembentukan dan pembekalan tim & Berhasil terbentuk tim \\
\hline & & $\begin{array}{l}\text { Menentukan tempat sosialisasi }, \\
\text { membuata jadwal serta pembelian } \\
\text { peralatan dan bahan }\end{array}$ & $\begin{array}{l}\text { Mendapatkan tempat } \\
\text { sosialisasi , berhasil } \\
\text { membuat jadwal serta } \\
\text { didaptkan alat dan bahan } \\
\text { penunjang }\end{array}$ \\
\hline
\end{tabular}




\begin{tabular}{|l|l|l|l|}
\hline 3 & Pelaksanaan & & \\
\cline { 2 - 4 } & 1. Sosialisasi & $\begin{array}{l}\text { Melakukan sosialisasi } \\
\text { di balai Desa }\end{array}$ & $\begin{array}{l}\text { Memahami proses } \\
\text { metode pelaksanaan }\end{array}$ \\
\cline { 2 - 4 } & $\begin{array}{l}\text { 2. Pengaja } \\
\text { ran }\end{array}$ & $\begin{array}{l}\text { Mengajarkan cara pembuatan pupuk } \\
\text { organic dari kotoran sapi }\end{array}$ & $\begin{array}{l}\text { Memahami proses metode } \\
\text { pelaksanaan }\end{array}$ \\
\hline $\begin{array}{ll}\text { 3. Aplikasi } \\
\text { Pelatihan pengaplikasian pupuk } \\
\text { organic pada tanaman }\end{array}$ & $\begin{array}{l}\text { Mampu menerapkan metode } \\
\text { pelaksanaan pada }\end{array}$ \\
\hline & Evaluasi & $\begin{array}{l}\text { Memberi solusi pada permasalahan } \\
\text { yang ada }\end{array}$ & $\begin{array}{l}\text { Meningkatnya pendapatan } \\
\text { masyarakat dan program } \\
\text { terus berlanjut }\end{array}$ \\
\hline
\end{tabular}

\subsection{Tahap Perencanaan}

Tahap perencanaan dilakukan dengan pembentukan dan pembekalan tim PKM-M yang terdiri dari 4 orang dan selanjutnya menyusun proposal yang kemudian diajukan. Program ini akan dilaksanakan dari bulan Desember 2018 sampai Januari 2019.

\subsection{Tahap Persiapan}

Tahap persiapan dilaksanakan selama satu minggu yaitu berupa melakukan kesepakatan kerjasama dengan penduduk Desa Nagasari, penyusunan jadwal kegiatan, penentuan tempat sosialisasi yaitu di Balai Desa Nagasari serta pembelian peralatan dan bahan.

\subsection{Tahap Pelaksanaan}

1. Sosialisasi

Tahap sosialisasi mencakup pengenalan pupuk organik yang dapat diolah dari kotoran sapi menjadi pupuk organik, sehingga diharapkan Desa tersebut dapat memproduksi pupuk organik sendiri yang bermanfaat. Tahap ini bertujuan sebagai gambaran awal rencana program pembuatan pupuk organik pada masyarakat serta meningkatkan minat masyarakat untuk bekerjasama membuat pupuk organik.

\section{Pengajaran}

Tahap pengajaran dilakukan dengan cara mengumpulkan seluruh warga dan memberikan pengajaran berupa praktek.

a) Mempersiapkan kotoran sapi

b) Mempersiapkan larutan penunjang

c) Menentukan takaran larutan

d) Proses fermentasi

e) Proses pengemasan

f) Tahap Aplikasi

Tahap aplikasi merupakan tahap terakhir dari program MASA PUBER. Tahap ini mencakup pendampingan pengolahan kotoran sapi menjadi pupuk organik hingga pengaplikasiannya terhadap jenis tanaman serta pengemasan pupuk untuk didistribusikan. 


\subsection{Tahap Evaluasi}

Tahap evaluasi dilakukan untuk memberikan solusi dari permasalahan yang dihadapi oleh masyarakat dalam proses produksi atau pembuatan, pengaplikasian terhadap tanaman hingga pemasaran. Indikator keberhasilan pada tahap ini adalah didapatkan solusi dari permasalahan tersebut dan menjadi acuan untuk ke depannya dan juga terus berkembang dan berjalannya program ini.

\subsection{Jadwal Kegiatan}

Tabel 4.2

Jadwal kegiatan

\begin{tabular}{|c|c|c|c|c|c|c|c|}
\hline \multirow{2}{*}{ N } & \multirow[b]{2}{*}{ Jenis Kegiatan } & \multicolumn{4}{|c|}{ Minggu ke } & & \multirow[b]{2}{*}{ PJ } \\
\hline & & 1 & 2 & 3 & 4 & 5 & \\
\hline \multirow{2}{*}{1.} & Perencanaan & & & & & & \\
\hline & Pembentukan tim & & & & & & All \\
\hline \multirow{4}{*}{2.} & Persiapan & & & & & & \\
\hline & Pengaturan jadwal & & & & & & IS \\
\hline & Penentuan tempat & & & & & & WR \\
\hline & $\begin{array}{l}\text { Pembelian bahan dan } \\
\text { peralat } \\
\text { an }\end{array}$ & & & & & & AW \\
\hline \multirow{8}{*}{3.} & Pelaksanaan & & & & & & \\
\hline & Sosialisasi & & & & & & \multirow{2}{*}{ All } \\
\hline & Pengajaran & & & & & & \\
\hline & $\begin{array}{l}\text { Aplika } \\
\text { si }\end{array}$ & & & & & & \\
\hline & Proses pembuatan & & & & & & \multirow{4}{*}{ All } \\
\hline & $\begin{array}{l}\text { Proses pengaplikasian } \\
\text { pada tanaman }\end{array}$ & & & & & & \\
\hline & Proses pengemasan & & & & & & \\
\hline & $\begin{array}{l}\text { Evalua } \\
\text { si }\end{array}$ & & & & & & \\
\hline & & & & & & & \\
\hline
\end{tabular}

Keterangan :

All

IS

SM
: Semua member tim

: Istianah Setyaningsih

: Sri Mulyati
AW : Alfyyah Widad

WR : Wahidasa Ridwan 


\subsection{ANGGARAN BIAYA}

Tabel 4.3

Tabel Anggaran Biaya

\begin{tabular}{|c|c|c|c|}
\hline $\begin{array}{l}\mathrm{N} \\
\mathrm{O}\end{array}$ & JENIS BIAYA & Satuan & JUMLAH (RP) \\
\hline \multirow{4}{*}{1 . } & \multicolumn{3}{|c|}{ Bahan - bahan } \\
\hline & EM4 & $1 \mathrm{btl}$ & 30.000 \\
\hline & Gula Pasir & $1 / 4 \mathrm{gr}$ & 4.000 \\
\hline & Bubuk Kunyit & $5 \mathrm{Sct}$ & 5.000 \\
\hline \multicolumn{4}{|c|}{ Kemasan } \\
\hline \multirow[t]{2}{*}{2.} & Botol & 5 btl & 10.000 \\
\hline & Plastik Mika & $1 / 2$ lusin & 4.000 \\
\hline & Total & & 53.000 \\
\hline
\end{tabular}

\section{Proses Produksi Dan Hasil}

\subsection{Alat}

Berikut adalah alat yang diperlukan dalam pengolahan kotoran sapi menjadi pupuk organik :

1. Ember

2. Karung

3. Literan

4. Alat Pengaduk

5. Cangkul

\subsection{Bahan}

Adapun bahan yang digunakan adalah sebagai berikut :
1. Kotoran Sapi
$=1 \mathrm{~kg}$
2. Dedak
$=900$ gram
3. EM4
$=0,015$ Liter
4. Gula pasir
$=0,03$ gram
5. Air
$=2$ liter

\subsection{Cara Membuat}

1. Kotoran sapi dicampur dengan dedak, aduk sampai rata dalam wadah A

2. Membuat larutan dengan komposisi EM4,gula,dan air didalam wadah B

3. Campur wadah A dan B

4. Tambahkan air, aduk merata

5. Masukan campuran tersebut kedalam wadah dan kemudian tutup rapat. Tunngu sampai 1-3 minngu

6. Setiap 3 hari, pupuk diaduk kemudian tutup kembali 
7. Lakukan pemisahan, pupuk yang mengendap dijadikan pupuk organik padat dan yang cair menjadi pupuk organik cair.

\subsection{Cara pengaplikasian pupuk pada tanaman:}

1. Pengaplikasian pupuk organik padat pada tanaman :Berikanpupuk organik padat secukunya pada tanaman

2. Pengaplikasian pupuk organik cair: Siramkan pupuk organik cair yang bercampur air ke bagian akar tanaman.

3. Penggunaan pupuk jangan terlalu banyak, dan penyiraman dilakukan secara teratur.

\subsection{Hasil}

Berikut ini adalah hasil yang didapat dari kegiatan pengolahan kotoran sapi, diantaranya :

1. Warga desa Nagasari dapat memahami pemanfaatan kotoran sapi yang sebelumnya tidak terpakai dan hanya menjadi limbah di sembarang tempat.

2. Warga desa Nagasari menyadari kesadaran dari keunggulan pupuk organik dibanding pupuk anorganik

3. Pengolahan pupuk organik dari kotoran sapi menjadi kegiatan warga desa Nagasari di waktu luang disamping profesinya yang mayoritas adalah petani.

4. Warga desa Nagasari mulai meminimalisir pembelian pupuk anorganik dan menggunakan pupuk organik untuk mengurangi biaya pengolahan pertanian.

5. Menjalin tali silaturahmi yang lebih erat antar warga desa Nagasari .

6. Tanaman yang menggunakan pupuk organik lebih subur dan segar meskipun periode panen
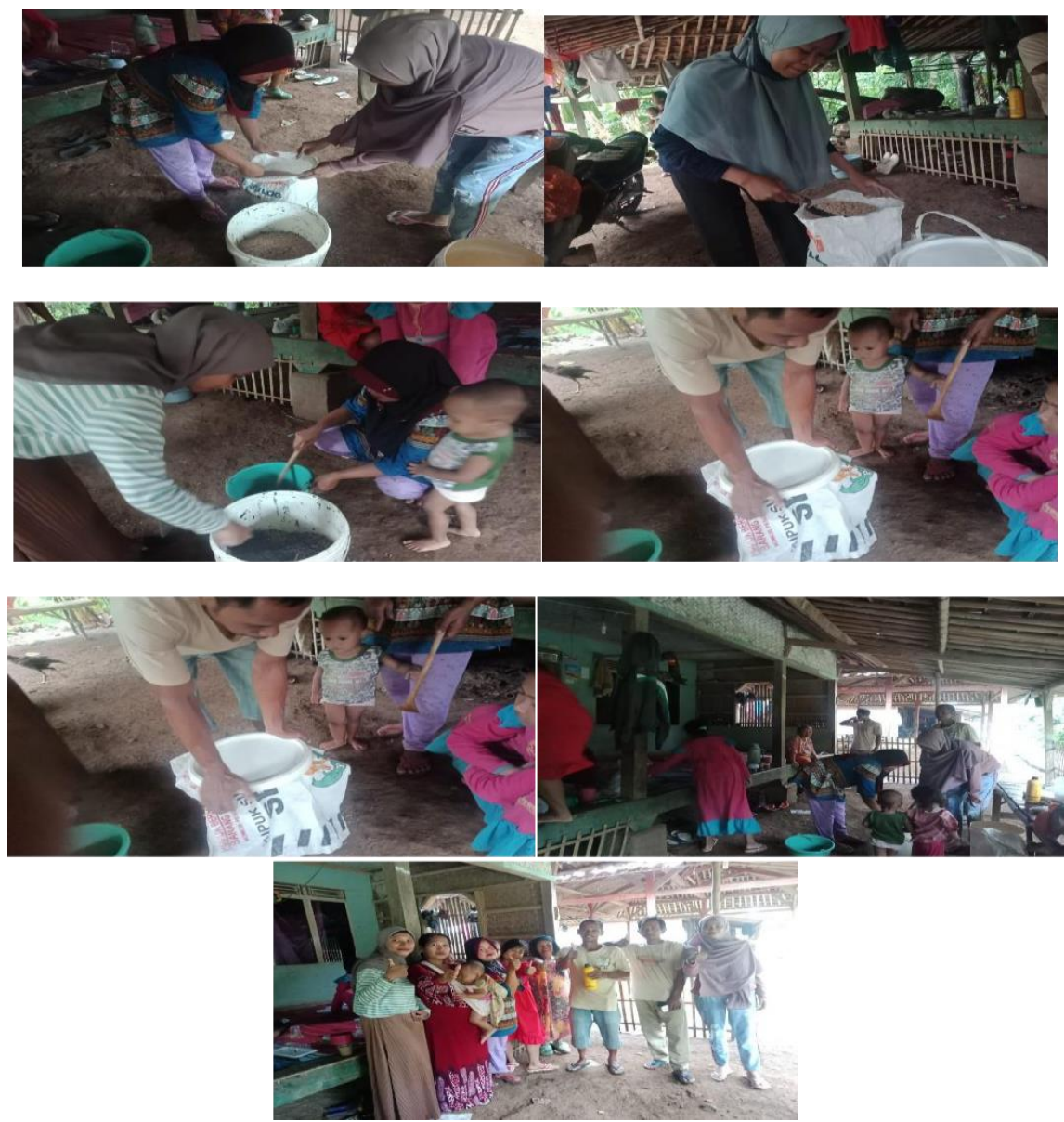


\section{Penutup}

\subsection{Kesimpulan}

Pengolahan kotoran sapi menjadi pupuk organik yang bermanfaat di desa Nagasari ini mendapatkan feedback yang baik dari warga desa setempat. Sehingga proses program pengabdian dapat berjalan dengan baik dan lancar. Berikut ini adalah kesimpulan yang dapat diambil dari pengolahan kotoran sapi menjadi pupuk organik yang bermanfaat :

1. Warga desa Nagasari mayoritas berprofesi sebagai petani.

2. Hampir semua warga memiliki ternak hewan seperti kambing dan sapi.

3. Selama ini kotoran sapi hanya dijadikan sebagai limbah yang tidak bermanfaat (Disimpan disembarang tempat, dibuang ke sungai atau perairan dan di bakar).

4. Kepercayaan warga terhadap pupuk anorganik cukup tinggi sehingga membutuhkan penjelasan yang lebih akurat mengenai pentingnya penggunaan pupuk organik.

5. Warga desa mulai memahami manfaat yang terkandung dalam pupuk organik dari kotoran sapi untuk hasil pertanian mereka.

6. Budget pengolahan pertanian berkurang dengan mulai menggunakan pupuk organik dari kotoran sapi.

7. Proses pengolahan kotoran sapi menjadi pupuk organik tidak sulit dan hanya membutuhkan bahan serta alat sederhana.

8. Anggaran yang dibutuhkan dalam pengolahan kotoran sapi menjadi pupuk tidak mahal.

9. Bahan yang digunakan untuk pengolahan kotoran sapi menjadi pupuk mudah ditemui.

10. Hasil tanaman menggunakan pupuk organik lebih segar dan sehat dibandingkan pupuk anorganik.

11. Warga desa Nagasari mengolah pertaniannya sesuai musim dan kondisi sehingga pemanfaatan lahan berkurang.

\subsection{Saran}

1. Para warga sebaiknya menggunakan pupuk organik dari hasil yang mereka buat

2. Pupuk yang sudah jadi dapat di perjualbelikan untuk menambah nilai ekonomis

3. Lebih gencar dalam promosi penggunaan pupuk organic

4. Warga harus lebih perhatian terhadap kotoran sapi yang dibuang.

5. Warga dapat mengajarkan kepada warga lainya agar dapat diproduksi secara masal.

6. Warga dapat menamam tanaman disekitar rumah mereka dan mengaplikasikan pupuk yang mereka buat.

7. Warga diharapkan dapat mengurangi penggunaan pupuk anorganik.

8. Adanya pemahaman mengenai dampak buruk pembuangan kotoran sapi ke sungai atau perairan.

9. Warga dapat lebih menjaga kebersihan lingkungan.

10. Warga sebaiknya lebih memanfaatkan lahan yang ada untuk pertanian dan tidak hanya musiman atau menyesuaikan kondisi.

\section{Daftar Pustaka}

Yuliarti, Nurheti. 2009. 1001 Cara Menghasilkan Pupuk Organik Cair. Yogyakarta : Lily Publisher

Hayati, Erita.T. Mahmud. Riza Fazil.2012.Pengaruh Jenis Pupuk Organik dan Vairetas Terhadap Pertumbuhan dan Hasil Tanaman Cabai.Jurnal Floratek:Fakultas Pertanian, Universitas Syiah Kuala 
Suwahyono, Untung.2011. Petunjuk Praktis Penggunaan Pupuk Organik Secara Efektif dan Efisien.Bandung : Penebar Swadaya

Hartatik,Wiwik,Husnain,Ladiyani.2015. Pernananan Pupuk Organisk dalam Peningkatan Produktivitas Tanah dan Tanaman. Jurnal Sumberdaya Lahan:Balai Besar Penelitian dan Pengembangan Sumberdaya Lahan Pertanian

Indrianai. Yovita Hety.2003.Membuat Kompos Secara Alami.Penebar Swadaya:Jakarta

Adityawarman,A,2015. Pengolahan Limbah Ternak Sapi Secara Sederhana di Desa Pattalassang Kabupaten Sinjai Sulawesi Selatan. Jurnal Ilmu produksi dan Teknologi Hasil Pertanian IPB 